Shah Faisal, Junaidi Khotib and Elida Zairina*

\title{
Knowledge, attitudes, and practices (KAP) towards COVID-19 among university students in Pakistan: a cross-sectional study
}

https://doi.org/10.1515/jbcpp-2020-0436

Received December 22, 2020; accepted January 29, 2021

\section{Abstract}

Objectives: Pakistan has taken unprecedented measures to control the spread of COVID-19. Complete lockdown followed by smart lockdown and quarantine centres was established. Their awareness and attitude towards COVID-19 had an impact on the individual behaviour of the precautionary measures. The current study examined the knowledge, attitudes and practices of university students in Pakistan.

Methods: An online cross-sectional study was conducted among university students in Pakistan. A questionnaire containing demographic and KAP information related to COVID-19 has been created.

Results: A total of 358 students responded to the survey, and 353 participants completed the study. Among the respondents, $61.5 \%$ were male, $76.8 \%$ were single, and $58.4 \%$ enrolled in a bachelor's degree. The results showed that most of the respondents $(68 \%)$ had good knowledge about COVID-19, while the overall knowledge score was $8.78 \pm 1.63$ (range 1-10). The majority of the respondents (90.9\%) were aware of COVID-19, 95.8\% knew the sign and symptoms, and $83 \%$ of them knew about its transmission. We found a significant difference in knowledge scores across education and area of study $\mathrm{p}<0.05$. More than half $(53.5 \%)$ of the respondents were satisfied with the facilities provided by the government of

*Corresponding author: Elida Zairina, Department of Pharmacy Practice, Faculty of Pharmacy, Universitas Airlangga, Surabaya, Indonesia; Center for Patient Safety Research, Universitas Airlangga, Surabaya, Indonesia; and Innovative Pharmacy Practice and Integrated Outcomes Research (INACORE) Group, Universitas Airlangga, Surabaya, Indonesia, Phone: +62 0315933150 , E-mail: elida-z@ff.unair.ac.id. https://orcid.org/0000-0003-0845-4640

Shah Faisal, Magister Program of Pharmaceutical Sciences, Faculty of Pharmacy, Universitas Airlangga, Surabaya, Indonesia Junaidi Khotib, Department of Pharmacy Practice, Faculty of Pharmacy, Universitas Airlangga, Surabaya, Indonesia
Pakistan. The average practices score among the students was $5.08 \pm 1.312$. A significant difference was found among practice score and area of study $\mathrm{p}<0.05$.

Conclusions: Most of the students have an adequate level of knowledge and are doing better preventive measures against COVID-19. Health education initiatives are required to ensure best practice among the high-risk groups.

Keywords: attitudes; COVID-19; knowledge; Pakistan; practices; university students.

\section{Introduction}

An outbreak of enigmatic pneumonia, characterized by fever, dry cough, fatigue, and gastrointestinal symptoms, was reported in China in December 2019 [1]. Later, following the local health authority's announcement of an epidemiological warning on 1 January 2020, the market was closed [2]. Fever, cough mostly dry, fatigue, muscle aches, and difficulty breathing are the main clinical manifestations of this profoundly infectious disease, while the advanced stage of the disease is described as respiratory discomfort, septic shock, and coagulation problems [3, 4]. The World Health Organization (WHO) announced a global public health emergency on 30 January 2020 [5].

The Government of Pakistan and the Ministry of Health have taken unprecedented steps to restrict the spread of the virus in the country. These include a complete lockdown at the start of the pandemic, followed by a smart lockdown in major cities and educational institutions' closure [6]. The Ministry of National Health Services Regulation and Coordination (MoNHSRC) report identified 295,636 confirmed cases by 30 August 2020. The total number of cases in Sindh provinces was 129,268 among all the Pakistan regions, with 2,398 reported deaths. Punjab has 96,741 confirmed cases and 2,196 deaths, and Khyber Pakhtunkhwa has 36,017 confirmed cases and 1,250 deaths, Balochistan has 12,842 confirmed cases and 141 reported deaths, Gilgit Baltistan has 2,863 confirmed cases and 67 deaths, Azad Jammu Kashmir has 2,294 confirmed cases and 61 deaths, while the Islamabad Capital Territory has 15,611 confirmed cases and 175 deaths [7]. 
The pandemic has put the education system in a difficult situation, especially for university students who were at their time free but with limited experiences. Their behaviours and attitudes were assumed to be affected by the outbreak. The outbreak of SARS in 2003 suggested that public knowledge and attitudes towards the pandemic were linked to panic emotions, which in turn had an impact on measures to control the pandemic. As a result, the assessment of knowledge and attitudes about COVID-19 insights, into preventive practices could be gained. During the pandemic, the government of Pakistan closed down educational institutions. Knowing about the 'student's' knowledge $(\mathrm{K})$, attitudes $(\mathrm{A})$, and practices $(\mathrm{P})$ against COVID-19 will help governments and policymakers to control the pandemic by targeting vulnerable populations. The study aimed to evaluate the student's knowledge (K), attitudes (A), and practices (P) against COVID-19.

\section{Materials and methods}

An online cross-sectional survey was conducted between 15 June and 20 July 2020 at various universities in Pakistan. The data was collected using a random sampling method. The questionnaire was based on information provided on the WHO and the Government of Pakistan websites for COVID-19 [8, 9]. The questionnaire was not validated and was used to collect information from students about awareness of COVID-19. The online link to the questionnaire was shared with university students through social media (WhatsApp and Facebook messenger). The questionnaire included the informed consent of the participants prior to the completion of the questionnaire. The researcher inserted a brief introduction to the background, purpose, procedure, voluntary participation, confidentiality, participation notes and completion of the questionnaire. The first part of the questionnaire concerned the students' demographic characteristicsthe second part of the questionnaire (K1-K10) dealt with the knowledge and transmission of COVID-19. Every question was answered as yes/no and not sure. The score of 1 was given for each correct answer and 0 for each incorrect/not sure answer. A total score of $\geq 8$ was considered good knowledge; a score of 7 was deemed to be fair, while a score of $\leq 6$ was regarded as poor knowledge. The third part of the study consisted of two questions (A1-A2) about attitudes towards COVID-19 with a yes/no answer choice. The fourth part comprised six questions to the practices toward COVID-19, which were answered as yes/no. A mean score $\geq 5$, indicated good practices against COVID-19, a score of 4 as fair practices, while three or less than 3 showed poor practices among the university students.

\section{Statistical analysis}

The data were analysed using the statistical package for social science (SPSS) version 25.0. A descriptive analysis was used to measure the study characteristics, the level of knowledge, attitudes, and practices. Standard deviation and mean were used to compare each variable based on demographic classification. In addition, the Mann Whitney test and ANOVA test with a 95\% confidence level were carried out to examine the difference between variables.

\section{Results}

A total of 358 respondents responded to the survey. Five respondents were not willing to participate, and 353 of the respondents completed the survey. The demographic characteristics of the respondents were shown in Table 1. The study showed that the majority of the respondents (68\%) had good knowledge of COVID-19. The mean knowledge score for COVID-19 was $8.78 \pm 1.63$ (range 1-10). The high knowledge score was in the 28-38 age group, with a mean score of $8.94 \pm 1.81$ SD. Ph.D. students have a high score of knowledge compared to master and bachelor students. Respondents in Azad Jammu Kashmir territory have higher knowledge score $(9.36 \pm 0.92)$ as compared to students in other regions. There was a significant difference in knowledge score across education and study province $(\mathrm{p}<0.05)$, as shown in Table 1.

while the percentage of respondents' level of practice is shown in Table 3.

Assessing the respondents' attitudes, $53.5 \%$ stated that they were satisfied with the facilities provided by the government of Pakistan. Responses to statements of attitudes can be seen in Figure 1.

The students' mean practice score was $5.08 \pm 1.312$ SD (Range 1-6), which showed that the students do better practices against the pandemic. The students from Azad Jammu Kashmir do better practices $5.45 \pm 1.21$ as compared to students in other provinces of the study. We found a significant difference in practice scores between the study area $(\mathrm{p}<0.05)$, as shown in Table 1 . The results of the student responses to COVID-19 practice statements were shown in Table 4, while the students' level of practice is shown in Table 3.

\section{Discussion}

Since the outbreak of COVID-19, it has promptly become a menace to public health and has led to massive socioeconomic damages worldwide. Strenuous measurements have been enforced, including lockdowns, social distancing, closing educational institutions, banning public gatherings, and establishing quarantine centres in Pakistan to mitigate the outbreak effectively. 
Table 1: Respondents demographics and scores of knowledge, attitudes, and practices toward COVID-19.

\begin{tabular}{|c|c|c|c|c|c|c|c|c|}
\hline \multirow[t]{2}{*}{ Demography } & \multirow[t]{2}{*}{ Frequency $(n=353)$} & \multirow[t]{2}{*}{ Percentage } & \multicolumn{2}{|c|}{ Knowledge score } & \multicolumn{2}{|c|}{ Attitude score } & \multicolumn{2}{|c|}{ Practice score } \\
\hline & & & Mean \pm SD & p-Value & Mean \pm SD & p-Value & Mean \pm SD & p-Value \\
\hline \multicolumn{9}{|l|}{ Gender } \\
\hline Female & 136 & 38.5 & $8.76 \pm 1.82$ & 0.369 & $1.04 \pm 0.87$ & 0.576 & $5.15 \pm 1,17$ & 0.630 \\
\hline Male & 217 & 61.5 & $8.79 \pm 1.50$ & & $0.99 \pm 0.87$ & & $5.03 \pm 1.392$ & \\
\hline \multicolumn{9}{|l|}{ Age group, years } \\
\hline $17-27$ & 285 & 80.5 & $8.74 \pm 1.59$ & 0.688 & $1.01 \pm 0.87$ & 0.073 & $5.07 \pm 1.36$ & 1.69 \\
\hline $28-38$ & 62 & 17.6 & $8.94 \pm 1.81$ & & $0.91 \pm 0.83$ & & $5.03 \pm 1.10$ & \\
\hline Above 39 & 7 & 2 & $8.86 \pm 1.57$ & & $1.71 \pm 0.75$ & & $6.00 \pm 0.00$ & \\
\hline \multicolumn{9}{|l|}{ Marital status } \\
\hline Single & 271 & 76.8 & $8.74 \pm 1.58$ & 0.612 & $0.99 \pm 0.86$ & 0.469 & $5.06 \pm 1.36$ & 0.625 \\
\hline Married & 81 & 22.9 & $8.88 \pm 1.81$ & & $1.04 \pm 0.89$ & & $5.15 \pm 1.13$ & \\
\hline Divorced & 1 & 0.4 & $10.00 \pm 00$ & & $2.00 \pm 0.00$ & & $4.00 \pm 0.00$ & \\
\hline \multicolumn{9}{|l|}{ Education } \\
\hline Bachelor & 206 & 58.4 & $8.64 \pm 1.76$ & 0.025 & $1.05 \pm 0.88$ & 0.187 & $5.04 \pm 1.36$ & 0.442 \\
\hline Master & 126 & 35.7 & $8.86 \pm 1.45$ & & $0.90 \pm 0.86$ & & $5.08 \pm 1.27$ & \\
\hline PhD & 21 & 5.9 & $9.62 \pm 1.63$ & & $1.19 \pm 0.81$ & & $5.43 \pm 0.97$ & \\
\hline \multicolumn{9}{|l|}{ Province } \\
\hline Azad Jammu Kashmir & 11 & 3.1 & $9.36 \pm 0.92$ & 0.034 & $1.00 \pm 1.00$ & 0.589 & $5.45 \pm 1.21$ & 0.001 \\
\hline Baluchistan & 22 & 6.2 & $7.86 \pm 1.93$ & & $1.18 \pm 0.85$ & & $4.14 \pm 1.45$ & \\
\hline Gilgit Baltistan & 6 & 1.7 & $7.83 \pm 2.40$ & & $1.16 \pm 0.98$ & & $4.00 \pm 1.78$ & \\
\hline Khyber-Pakhtunkhwa & 184 & 52.1 & $8.92 \pm 1.55$ & & $0.96 \pm 0.90$ & & $5.16 \pm 1.31$ & \\
\hline Punjab & 110 & 31.2 & $8.75 \pm 1.61$ & & $0.99 \pm 0.82$ & & $5.25 \pm 1.11$ & \\
\hline Sindh & 20 & 5.7 & $8.78 \pm 1.63$ & & $1.30 \pm 0.73$ & & $4.60 \pm 1.50$ & \\
\hline \multicolumn{9}{|l|}{ University } \\
\hline Private university & 120 & 34 & $8.67 \pm 1.57$ & 0.367 & $1.05 \pm 0.84$ & 0.468 & $5.06 \pm 1.32$ & 0.830 \\
\hline Public university & 233 & 66 & $8.83 \pm 1.66$ & & $0.98 \pm 0.88$ & & $5.09 \pm 1.30$ & \\
\hline
\end{tabular}

The respondents' responses to the knowledge statements were shown in Table 2, while the percentage of respondents' level of practice is shown in Table 3. Assessing the respondents' attitudes, 53.5\% stated that they were satisfied with the facilities provided by the government of Pakistan. Responses to statements of attitudes can be seen in Figure 1.

In this study, the students have good knowledge of COVID-19 as the mean knowledge score was $8.78 \pm 1.63$ (range 1-10). The overall correct student knowledge was $87.75 \%$. This study is in range with previous research conducted in Vietnam and China, where participants' correct knowledge score was high [10, 11]. We found a significant association in knowledge score between educational level and study area $(\mathrm{p}<0.05)$. The high study level was associated with high knowledge score of respondents. These results of this study are consistent with a study conducted in China [12]. Most of the respondents in this study (95.8\%) were aware of the disease's clinical signs and symptoms, and $89.5 \%$ were aware that there was no specific treatment as of the date of the survey. The results of this study are consistent with prior research conducted in Saudi Arabia [13].

The question from K6-K10 was about the mode of transmission where the overall score of respondents was $83 \%$. The majority of respondents $(94.3 \%)$ indicated that isolation and quarantine are common strategies that can help control the spread of diseases, while the correct score for human-to-human transmission by droplet and contaminated hand was $94.1 \%$. These results are supported by previous studies in Malaysia and Ethiopia [14, 15]. The correct scores of the respondents for the virus cannot be transmitted through mosquitos were $72.2 \%$. Our study result is in line with the study conducted in Nigeria [16]. The respondents' attitude towards the government approach to the pandemic was satisfactory. The responses to attitudes are different from the study conducted in China and Saudi Arabia, where most of the respondents were optimistic about the 'government's' approach to the pandemic [11, 13]. Students have shown better preventive practices to control the spread of the pandemic. The mean student preventive practice score was $5.08 \pm 1.312$ SD. The majority of respondents $(90.9 \%)$ indicated that they often wash their hands with soap for $20 \mathrm{~s}$, while $76.5 \%$ use sanitizers consistent with previous research [14]. The student's practices of avoiding crowded places were also high, as $88.1 \%$ reported avoiding crowded places, which is in line with the Malaysia study [14]. The majority of respondents (93.2\%) indicated that they avoided contact with 
Table 2: Knowledge of the students towards COVID-19.

Questions

K1. COVID-19 is an infectious disease caused by a newly discovered coronavirus.

Not sure

K2. The main symptoms of coronavirus include coughing, shortness of breath, hot fever, and sore throat.

Yes

No

Not sure

K3. Presently, there are no vaccines that protect against the disease.

Yes

K4. There is no specific treatment. A supportive treatment use to reduce the symptoms.

Yes

No

Not sure

K5. People with chronic lung disease or moderate to severe asthma are at high risk for severe illness from COVID-19.

K6. People with weak immune system with diseases like cancer, smoking, organ transplantation, poorly controlled HIV, and prolonged use of corticosteroids had more risk for severe problems from COVID-19.

No

Not sure

K7. It's likely that the virus is originated in an animal, and then spread to humans.

Yes

No

Not sure

K8. COVID-19 cannot be transmitted through mosquitos.

No

Not sure

K9. COVID-19 spreads through contaminated droplets from infected persons (through coughing or sneezing) or contaminated hands.

Yes

No

K10. Isolation and quarantine are common strategies that can help to limit the spread of the virus.

Yes

No 
Are you satisfied with the facilities provided by the government of Pakistan against the pandemic of COVID-19?

353 responses

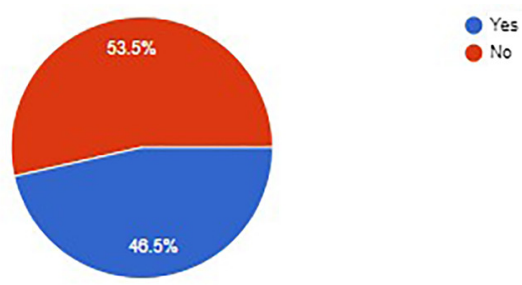

Do you believe that COVID-19 will be controlled in Pakistan very soon?

353 responses

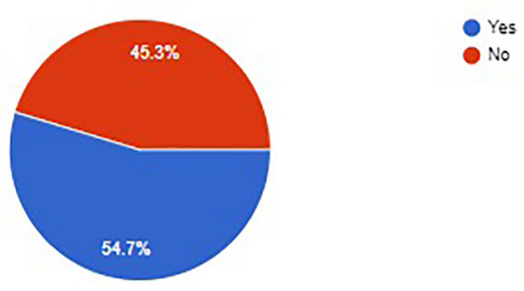

Table 3: Percentage of level of knowledge, and practices of the respondents.

\begin{tabular}{llrr}
\hline Variable & Level & Frequency, $\mathbf{~}$ & Percentage, \% \\
\hline Knowledge & Poor knowledge & 36 & 10.2 \\
& Fair knowledge & 77 & 21.8 \\
& Good knowledge & 240 & 68 \\
Practices & Poor practice & 43 & 12.2 \\
& Fair practice & 39 & 11 \\
& Good practice & 271 & 76.8 \\
\hline
\end{tabular}

Figure 1: Attitudes towards COVID-19 by the students

people who respiratory illness, symptoms, and covered their nose and mouth while sneezing which is in line with the study conducted in South Korea [17].

\section{Limitation of the study}

In this study, most of the respondents were from two provinces Khyber-Pakhtunkhwa, and Punjab, which is

Table 4: Respondents practices against COVID-19.

\begin{tabular}{|c|c|c|}
\hline Questions & Frequency & Percentage \\
\hline \multicolumn{3}{|c|}{ I wash my hands often with soap for $20 \mathrm{~s}$. } \\
\hline Yes & 321 & 90.9 \\
\hline No & 32 & 9.1 \\
\hline \multicolumn{3}{|c|}{ I use sanitizer when soap and water are not available. } \\
\hline Yes & 270 & 76.5 \\
\hline \multicolumn{3}{|c|}{ No } \\
\hline \multicolumn{3}{|c|}{ I avoid crowded places (social distancing). } \\
\hline Yes & 311 & 88.1 \\
\hline No & 42 & 11.9 \\
\hline \multicolumn{3}{|c|}{ I avoid close contact with anyone showing symptoms of respiratory illness. } \\
\hline Yes & 329 & 93.2 \\
\hline No & 24 & 6.8 \\
\hline \multicolumn{3}{|c|}{ I do not share eating. } \\
\hline Yes & 239 & 67.7 \\
\hline No & 114 & 32.3 \\
\hline \multicolumn{3}{|c|}{$\begin{array}{l}\text { I cover my mouth and nose with a tissue (not by hands) while coughing } \\
\text { or sneezing }\end{array}$} \\
\hline Yes & 323 & 91.5 \\
\hline No & 30 & 8.5 \\
\hline
\end{tabular}


well-developed and has easy access to the Internet. The number of respondents from the least developed areas such as Baluchistan and Gilgit Baltistan was low due to limited Internet access, which may be considered as the study's limitation. Further studies are needed in these areas to evaluate the knowledge, attitudes and practices of students. Another shortcoming of the study may be the small number of respondents who participated in the study may be another shortcoming of this study.

\section{Conclusions}

The study showed a comprehensive assessment of the student's awareness of COVID-19 when all the institutions were closed. The results showed that most respondents have good knowledge of COVID-19 and follow precautionary practices to combat the rise of COVID-19. This study's results may be useful for policymakers and healthcare authorities on further health interventions, awareness campaigns toward COVID-19, and health education programs. Health education programs aimed at mobilizing and improving information related to COVID-19 are required, particularly for vulnerable groups, to increase their preventive practices.

Acknowledgments: The authors are very thankful to all the students for their voluntary participation in the study.

Research funding: None declared.

Author contributions: All authors have accepted responsibility for the entire content of this manuscript and approved its submission.

Competing interests: Authors state no conflict of interest. Informed consent: Informed consent was obtained from all individuals included in this study.

Ethical approval: The local Institutional Review Board deemed the study exempt from review since it is for the purpose of internal validation of the questionnaire for organization to get more data about international student awareness regarding COVID-19.

\section{References}

1. Yang X, Yu Y, Xu J, Shu H, Liu H, Wu Y, et al. Clinical course and outcomes of critically ill patients with SARS-CoV-2 pneumonia in Wuhan, China: a single-centered, retrospective, observational study. Lancet Respir Med 2020; 8:475-81.
2. World Health Organization. Novel coronavirus (2019-nCoV) situation report - 3, 23 January 2020. Available from: https:// apps.who.int/iris/bitstream/handle/10665/330762/ nCoVsitrep23Jan2020-eng.pdf [Accessed 20 June 2020].

3. Novel CPERE. The epidemiological characteristics of an outbreak of 2019 novel coronavirus diseases (COVID-19) in China. Zhonghua Liuxingbingxue Zazhi 2020;41:145-51.

4. Chen N, Zhou M, Dong X, Qu J, Gong F, Han Y, et al. Epidemiological and clinical characteristics of 99 cases of 2019 novel coronavirus pneumonia in Wuhan, China: a descriptive study. Lancet 2020;395:507-13.

5. World Health Organization. 2019-nCoV outbreak is an emergency of international concern. Availabale from: http://www.euro.who. int/en/health-topics/emergencies/pages/news/news/2020/01/ 2019-ncov-outbreak-is-an-emergency-of-international-concern [Accessed 22 July 2020].

6. Dawn. 'Smart lockdown' begins in Karachi's Covid-19 hotspots. Available from: https://www.dawn.com/news/1564343 [Accessed 22 July 2020].

7. Ministry of National Health Services Regulation and Coordination (MoNHSRC). COVID-19 cases in Pakistan 2020. Available from: http://covid.gov.pk/stats/pakistan [Accessed 30 Aug 2020].

8. World Health Organization. Overveiw of corona virus. Available from: https://www.who.int/health-topics/coronavirus\#tab=tab_ 1 [Accessed 12 July 2020].

9. Government of Pakistan. Know about COVID-19. Available from: http://covid.gov.pk/ [Accessed 12 July 2020].

10. Huynh G, Nguyen TNH, Vo KN, Pham LA. Knowledge and attitude toward COVID-19 among healthcare workers at District 2 Hospital, Ho Chi Minh City. Asian Pac J Trop Med 2020;13:260.

11. Zhong BL, Luo W, Li HM, Zhang QQ, LiuXG, Li WT, et al. knowledge, attitudes, and practices towards COVID-19 among Chinese residents during the rapid rise period of the COVID-19 outbreak: a quick online cross-sectional survey. Int J Biol Sci 2020;16: 1745-52.

12. Li ZH, Zhang XR, Zhong WF, Song WQ, Wang ZH, Chen Q, et al. Knowledge, attitudes, and practices related to Coronavirus disease 2019 during the outbreak among workers in China: a large cross-sectional study. PLoS Neglected Trop Dis 2020;14: e0008584.

13. Al-Hanawi MK, Angawi K, Alshareef N, Qattan AM, Helmy HZ, Abudawood Y, et al. Knowledge, attitude and practice toward COVID-19 among the public in the Kingdom of Saudi Arabia: a cross-sectional study. Publ Health Forum 2020;8:217.

14. Azlan AA, Hamzah MR, Sern TJ, Ayub SH, Mohamad E. Public knowledge, attitudes and practices towards COVID-19: a crosssectional study in Malaysia. PloS One 2020;15:e0233668.

15. Akalu Y, Ayelign B, Molla MD. Knowledge, attitude and practice towards COVID-19 among chronic disease patients at Addis Zemen Hospital, Northwest Ethiopia. Infect Drug Resist 2020;13: 1949-60.

16. Reuben RC, Danladi MM, Saleh DA, Ejembi PE. Knowledge, attitudes and practices towards COVID-19: an epidemiological survey in North-Central Nigeria. J Community Health 2020: 1-14.

17. Park JH, Cheong HK, Son DY, Kim SU, Ha CM. Perceptions and behaviors related to hand hygiene for the prevention of H1N1 influenza transmission among Korean university students during the peak pandemic period. BMC Infect Dis 2010;10:222. 